University of Nebraska - Lincoln

DigitalCommons@University of Nebraska - Lincoln

$4-9-2004$

\title{
The elimination of the influence of ambient environmental effects on the structure of 'inert' polymers
}

Luis G. Rosa

University of Nebraska-Lincoln, luis.rosa13@upr.edu

P.A. Jacobson

University of Nebraska-Lincoln

Raymond Lemoine

University of Nebraska-Lincoln

Peter A. Dowben

University of Nebraska-Lincoln, pdowben@unl.edu

Follow this and additional works at: https://digitalcommons.unl.edu/physicsdowben

Part of the Physics Commons

Rosa, Luis G.; Jacobson, P.A.; Lemoine, Raymond; and Dowben, Peter A., "The elimination of the influence of ambient environmental effects on the structure of 'inert' polymers" (2004). Peter Dowben Publications. 113.

https://digitalcommons.unl.edu/physicsdowben/113

This Article is brought to you for free and open access by the Research Papers in Physics and Astronomy at DigitalCommons@University of Nebraska - Lincoln. It has been accepted for inclusion in Peter Dowben Publications by an authorized administrator of DigitalCommons@University of Nebraska - Lincoln. 
Journal of

\section{Applied Crystallography}

ISSN 0021-8898

Received 2 February 2004

Accepted 17 May 2004

\section{The elimination of the influence of ambient environmental effects on the structure of 'inert' polymers}

\author{
Luis G. Rosa,* P. A. Jacobson, Raymond Lemoine and P. A. Dowben \\ Department of Physics, Behlen Laboratory of Physics, Center for Materials Research and Analysis, University of \\ Nebraska-Lincoln, Lincoln, Nebraska 68588-0111, USA. Correspondence e-mail: gabo@unlserve.unl.edu
}

(C) 2004 International Union of Crystallography Printed in Great Britain - all rights reserved

\begin{abstract}
The construction and use of a vacuum chamber suitable for conventional X-ray diffraction has revealed the influence of the ambient environment, including moisture, on the bulk structure of very thin polymer films. It is concluded that studies of thin film organic systems, even those thought not to be perturbed by ambient water vapor and other contaminants, may benefit from undertaking some studies in such small sample vacuum chambers.
\end{abstract}

\section{Introduction}

There is a tacit assumption, often used in structure studies of inert hydrophobic polymers, that there are few effects of the ambient environment, including moisture, on the bulk structure of the polymer. By building a vacuum chamber suitable for use in conventional X-ray diffraction we have been able to show that this is not so; indeed, ambient moisture can affect structure. In spite of the long history of water contact-angle measurements on organic surfaces and polymers, e.g. studies like those of Erbil et al. (1999), Yasuda et al. (1994) and Miyama et al. (1997), to cite just a very few examples among the vast number, there exist far fewer papers detailing water adsorption on any polymer surface (Akhremitchev et al., 1998; Bedrov et al., 1998; Bummer \& Knutson, 1990; Cadzerna \& Thomas, 1987; Carey \& Ferguson, 1996; Carey et al., 2000; Chan et al., 1996; Chen et al., 1999; Erbil et al., 1999; Harder et al., 1998; Hawkridge et al., 2002; Levshin et al., 2001; Miyama et al., 1997; Ong et al., 1993; Parker et al., 1994; Pertsin \& Grunze, 2000; Pike et al., 1996; Proost et al., 2000; Suzuki et al., 2002; Tingey \& Andrade, 1991; Toselli et al., 2001; Wang et al., 1997, 2000; Weikart et al., 1999; Yasuda, et al., 1991, 1994, 1995). There remains an absence of a detailed understanding of polymer surface adsorbate chemistry, commensurate with other areas of surface science.

In order to observe environmental effects on the bulk structure of very thin films of the ferroelectric copolymer vinylidene fluoride with trifluoroethylene (70\%:30\% and $80 \%: 20 \%$ ), a small stainless-steel vacuum chamber with a window that is largely transparent to X-rays, contributing little scattering signal at the scattering angle of interest, was constructed, much like similar chambers described in the literature (Toyoshima et al., 1991; Mudd et al., 1987). Because of the small $\mathrm{X}$-ray cross section of ultra thin $(<50 \mathrm{~nm})$ main group element polymers, standard Be windows (Toyoshima et al., 1991; Bernard et al., 1999; Dennison et al., 1992) are inappropriate, while incorporation of the $\theta-2 \theta$ X-ray diffractometer directly into an ultra-high-vacuum system (Johnson \& Johnson, 1988) is not always practical.

Our goal was to modify a $\theta-2 \theta$ Rigaku D/Max-B X-ray diffractometer through the addition of a vacuum chamber with heating and cooling capabilities, not unlike that previously reported (Toyoshima et al., 1991), but with Mylar windows suitable for diffraction studies of organic systems (Mudd et al., 1987). Vacuum provides a reduction of ambient vapor pressure on the surface and elimination of consider- able amounts of gases that might be absorbed by the polymer, or indeed any substrate (Toyoshima et al., 1991; Bernard et al., 1999; Dennison et al., 1992; Johnson \& Johnson, 1988), and thus perturb the structure or X-ray scattering intensities.

\section{Vacuum chamber and experiment}

The chamber was built in order to fit the rotating stage on the Rigaku D/Max-B X-ray diffractometer. Top, side and back views of the chamber are shown in Fig. 1. The chamber was made small enough in order to reduce the weight on the stage. An aperture for a window was required, allowing scanning angles from 0 to $180^{\circ}$ from where we obtain information on the lattice spacing in the normal direction. The
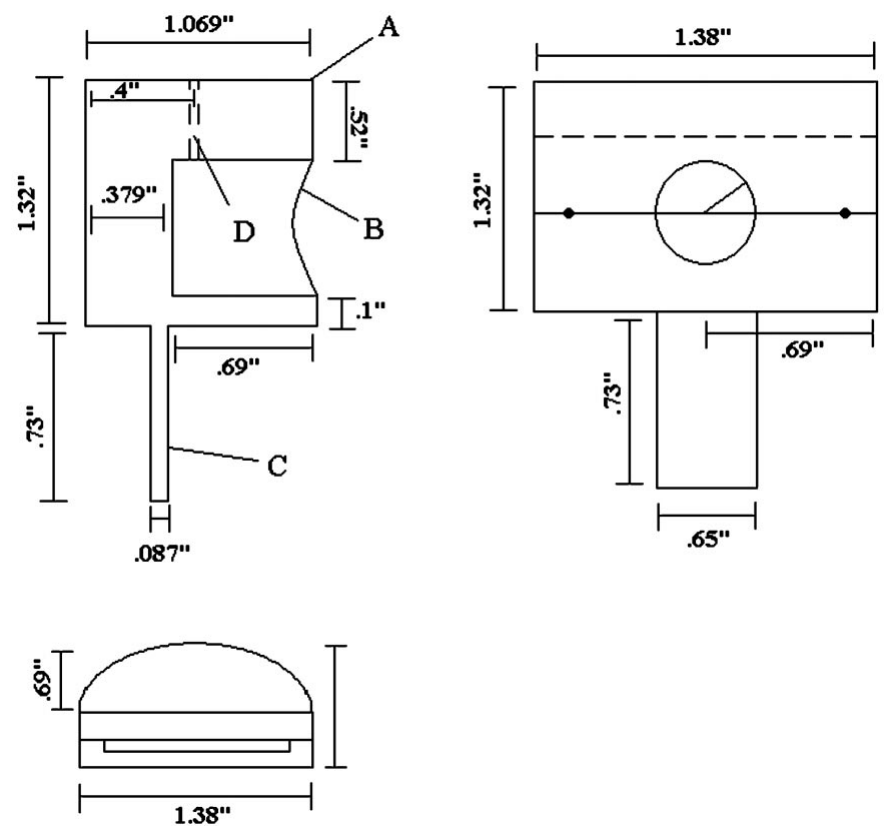

Figure 1

Side, back and top views of the stainless-steel X-ray diffraction vacuum chamber. $A$ : stainless-steel chamber; $B$ : Mylar window; $C$ : chamber holder; $D$ : hole for a vacuum valve. 
aperture was covered with a sheet of Mylar (0.013 mm thickness), affixed to the chamber with commercial adhesive, based on cellulose nitrate $\left[\mathrm{C}_{6} \mathrm{H}_{8}\left(\mathrm{NO}_{2}\right)_{2} \mathrm{O}_{5}\right]$, dissolved in acetone and butyl acetate. This particular adhesive was chosen as vacuum sealant because the solubility of the adhesive compound in acetone permitted facile reuse of the various chamber components. Once cured, the binder between the Mylar window and the steel frame of the chamber could hold a vacuum to $0.0133 \mathrm{~Pa}$ through a number of heating and cooling cycles, and was robust to the mechanical stresses of a number of pump cycles. A $6.73 \mathrm{~mm}$ aperture was made in the top of the chamber to fit a Swagelok vacuum valve and a mechanical roughing pump was used to produce the vacuum.

It is important that the transparent X-ray window did not obscure any of the diffraction peaks of the ferroelectric copolymer vinylidene fluoride with trifluoroethylene (70\%:30\% and 80\%:20\%). The main Mylar contribution to the $\theta-2 \theta$ diffraction intensity was in the vicinity of $26^{\circ}$, well away from the P(VDF-TrFE) copolymer film contributions near $20^{\circ}$ in the ferroelectric phase and $18-19^{\circ}$ in the paraelectric phase (Ducharme et al., 2002; Lovinger et al., 1984, 1983) (Fig. 2).

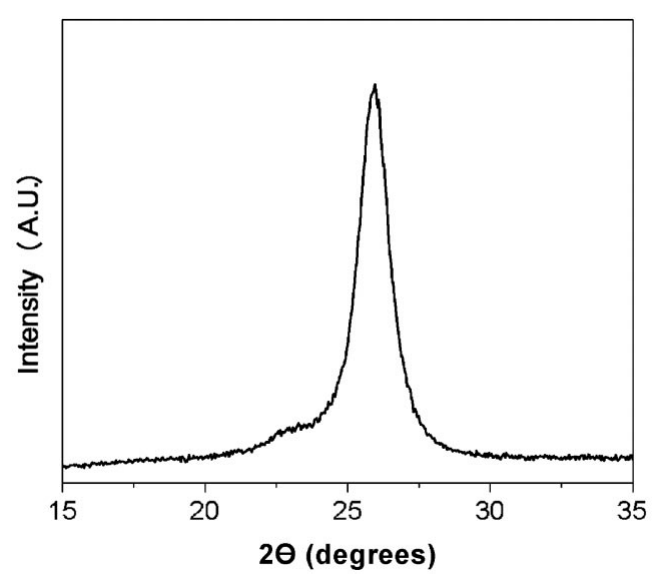

Figure 2

The X-ray diffraction peak of Mylar is observed at $26^{\circ}$, well away from the $\langle 110\rangle$ diffraction peak at $20-21^{\circ}$ of the ferroelectric copolymer vinylidene fluoride with trifluoroethylene $\mathrm{P}(\mathrm{VDF}-\mathrm{TrFE})$.

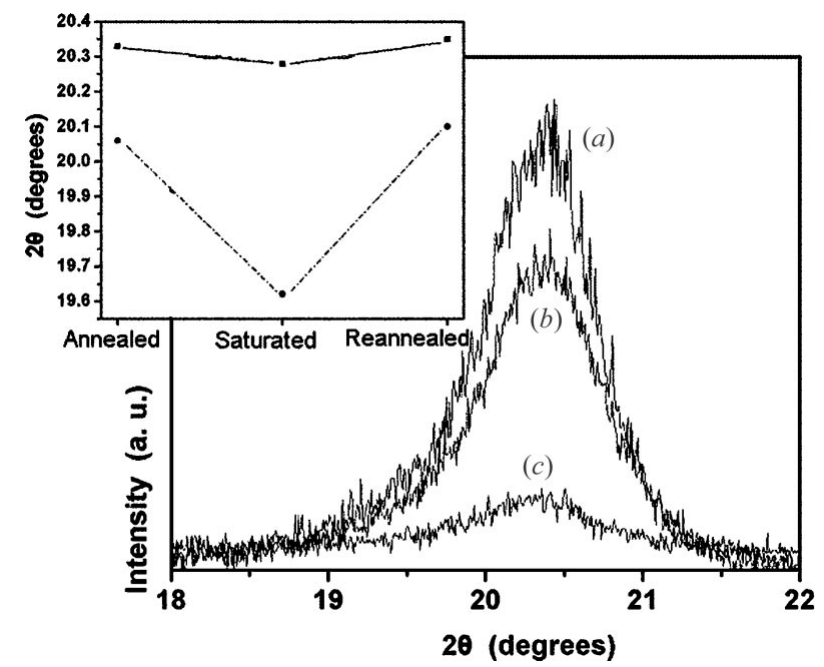

Figure 3

The $\langle 110\rangle$ diffraction peak at $20-21^{\circ}$ of the ferroelectric copolymer vinylidene fluoride with trifluoroethylene $\mathrm{P}(\mathrm{VDF}-\mathrm{TrFE})$ : $(a)$ annealed; $(b)$ reannealed; $(c)$ with water (saturated). Inset: reversibility of the bulk lattice parameter due to the process of absorption and desorption.
One of the common ambient gases in the atmosphere is water vapor. Water is not a standard solvent for poly(vinylidene fluoride), $\mathrm{P}(\mathrm{VDF})$, nor trifluoroethylene, but well ordered $\mathrm{P}(\mathrm{VDF}-\mathrm{TrFE})$ copolymer films swell when immersed in water (Jacobson et al., 2004). By comparing the $\theta-2 \theta$ X-ray diffraction lines from crystalline Langmuir Blodgett copolymer films of vinylidene fluoride with trifluoroethylene (70\%:30\% and 80\%:20\%) exposed to substantial amounts of water with those same films vacuum annealed and characterized in vacuum, we find that vinylidene fluoride with trifluoroethylene (70\%:30\% and 80\%:20\%) does absorb water. For the films annealed in vacuum as compared with the same films given a long exposure to water, there is an increase in the $\langle 110\rangle$ lattice interlayer spacing from 4.35 to $4.45 \AA$, and in some cases to as much as $4.55 \AA$, representing a change in bulk lattice parameter in the normal direction, as shown in Fig. 3. Water absorption also leads to a pronounced reduction in scattering intensity. This is seen in the X-ray diffraction measurements shown in Fig. 3. We note that the diffraction lines of vinylidene fluoride with trifluoroethylene (70\%:30\% and $80 \%: 20 \%$ ) are not obscured by the Mylar windows of our vacuum chamber in any significant way.

Water absorption is accompanied by film swelling as indicated by an increase in lattice spacing, sometimes by as much as $5 \%$. This water absorption, between 273 and $313 \mathrm{~K}$, is a result of intercalation or occupation of interstitial sites between the layers of the film, not just water molecules filling voids and defect sites alone. An increase in the film capacitance is observed, although the polymer chains retain the all-trans configuration of the ferroelectric phase (Jacobson et al., 2004). While it has been known that small amounts of water can be absorbed (Castela \& Simoes, 2003; Castela \& Simoes, 2002), reperforming structural studies in vacuo demonstrates that even hydrophobic polymers can absorb significant amounts of water and, presumably, other contaminants.

After annealing the film, both diffraction intensities and the original film-specific lattice constant are recovered, as indicated by the inset to Fig. 3. Thus water absorption is reversible and does not appear to lead to any permanent or persistent changes of the bulk structure of $\mathrm{P}(\mathrm{VDF}-\mathrm{TrFE})$ thin films, but the studies do indicate that good scattering signal intensity as well as assessment of the correct lattice spacing for this polymer are best obtained by undertaking the $\theta-2 \theta$ X-ray diffraction studies of these samples in vacuum.

As we have shown, simple vacuum chambers can be inexpensively constructed and easily added to many commercial X-ray diffractormeters. Studies of thin film organic systems, even those thought not to be perturbed by ambient water vapor and other contaminants, may benefit from undertaking some studies in such small sample vacuum chambers.

Support by the Petroleum Research Fund, the NSF 'QSPINS' MRSEC (DMR 0213808), and the Nebraska Research Initiative at the University of Nebraska is gratefully acknowledged.

\section{References}

Akhremitchev, B. B., Mohney, B. K., Marra, K. G., Chapman, T. M. \& Walker, G. C. (1998). Langmuir, 14, 3976-3982.

Bedrov, D., Pekny, M. \& Smith, G. D. (1998). J. Phys. Chem. B, 102, 996-1001. Bernard, P., Peters, K., Alvarez, J. \& Ferrer, S. (1999). Rev. Sci. Instrum. 70, 1478-1480.

Bummer, P. M. \& Knutson, K. (1990). Macromolecules, 23, 4357-4362.

Cadzerna, A. W. \& Thomas, T. M. (1987). J. Vac. Sci. Technol. A, 5, 2412-2416.

Carey, D. H. \& Ferguson, G. S. (1996). J. Am. Chem. Soc. 118, 9780-9781.

Carey, D. H., Grunzinger, S. J. \& Ferguson, G. S. (2000). Macromolecules, 33, 8802-8812. 
Castela, A. S. \& Simoes, A. M. (2002). Corrosion Sci. 45, 1647-1660.

Castela, A. S. \& Simoes, A. M. (2003). Corrosion Sci. 45, 1631-1646.

Chan, C. M., Ko, T. M. \& Hiraoka, H. (1996). Surface Sci. Rep. 24, 3-54.

Chen, Q., Zhang, D., Somorjai, G. \& Bertozzi, C. R. (1999). J. Am. Chem. Soc. 121, 446-447.

Dennison, J. R., Wang, S.-K., Dai, P., Angot, T., Taub, H. \& Ehrlich, S. N. (1992). Rev. Sci. Instrum. 63, 3835-3841.

Ducharme, S., Palto, S. P. \& Fridkin, V. M. (2002). Handbook of Thin Film Materials, Vol. 3, p. 545. New York: Academic Press.

Erbil, H. Y., McHale, G., Rowan, S. M. \& Newton, M. I. (1999). Langmuir, 15, 7378-7385.

Harder, P., Buck, M., Zolk, M., Lampert, A., Pertsin, A. \& Grunze, M. (1998). Abstr. Pap. Am. Chem. Soc. 215, 244-PHYS Part 2.

Hawkridge, A. M., Gardella, J. A. \& Toselli, M. (2002). Macromolecules, 35, 6533-6538.

Jacobson, P. A., Rosa, L. G., Othon, C. M., Kraemer, K., Sorokin, A. V., Ducharme, S. \& Dowben, P. A. (2004). Appl. Phys. Lett. 84, 88-90.

Johnson, R. W. \& Johnson, W. L. (1988). Rev. Sci. Instrum. 59, 2568-2572.

Levshin, N. L., Pestova, S. A. \& Yudin, S. G. (2001). Colloid J. 63, 205-208.

Lovinger, A. J. (1983). Macromolecules, 16, 1529-1534.

Lovinger, A. J., Johnson, G. E., Bair, H. E. \& Anderson, E. W. (1984). J. Appl Phys. 56, 2412-2418.

Miyama, M., Yang, Y. X., Yasuda, T., Okuno, T. \& Yasuda, H. K. (1997). Langmuir, 13, 5494-5503.

Mudd, C. P., Tipton, H., Parsegian, A. V. \& Rau, D. (1987). Rev. Sci. Instrum. 58, 2110-2114.
Ong, T. H., Davies, P. B. \& Bain, C. D. (1993). Langmuir, 9, 1836-1845.

Parker, J. L., Claesson, P. M., Wang, J. H. \& Yasuda, H. K. (1994). Langmuir, 10, 2766-2773.

Pertsin, A. J. \& Grunze, M. (2000). Langmuir, 16, 8829-8841.

Pike, J. K., Ho, T. \& Wynne, K. J. (1996). Chem. Mater. 8, 856-860.

Proost, J., Baklanov, M., Maex, K. \& Delaey, L. (2000). J. Vac. Sci. Technol. B, 18, 303-306.

Suzuki, Y., Li, J., Maekawa, Y., Yoshida, M., Maeyama, K. \& Yonezawa, N. (2002). Nippon Kagaku Kaishi No. 2, pp. 255-259.

Tingey, K. G. \& Andrade, J. D. (1991). Langmuir, 7, 2471-2478.

Toselli, M., Messori, M., Bongiovanni, R., Malucelli, G., Priola, A., Pilati, F. \& Tonelli, C. (2001). Polymer, 42, 1771-1779.

Toyoshima, N., Hoya, H. \& Ohshima, K.-I. (1991). J. Appl. Cryst. 24, 10741075.

Wang, R. L. C., Kreuzer, H. J. \& Grunze, M. (2000). Phys. Chem. Chem. Phys. 2, 3613-3622.

Wang, R. L. C., Kreuzer, H. J. \& Grunze, M. (1997). J. Phys. Chem. B, 101, 9767-9773.

Weikart, C. M., Miyama, M. \& Yasuda, H. K. (1999). J. Colloid Interface Sci. 211, 28-38.

Yasuda, H., Charlson, E. J., Charlson, E. M., Yasuda, T., Miyama, M. \& Okuno, T. (1991). Langmuir, 7, 2394-2400.

Yasuda, H., Okuno, T., Sawa, Y. \& Yasuda, T. (1995). Langmuir, 11, 32553260 .

Yasuda, T., Miyama, M. \& Yasuda, H. (1994). Langmuir, 10, 583-585.

Yasuda, T., Okuno, T. \& Yasuda, H. (1994). Langmuir, 10, 2435-2439. 